\title{
When Qualitative Research is Taught Virtually: Drawing on Experiential Design to Build Deeper Knowledge of Qualitative Observation
}

\author{
Joy C. Phillips \\ Drexel University \\ joy.phillips@drexel.edu \\ Kristine S. Lewis Grant \\ Drexel University \\ ksl33@drexel.edu \\ Kathy D. Geller \\ Drexel University \\ kathygeller@drexel.edu
}

\begin{abstract}
This essay discusses the EdD Program design and qualitative research course sequence at Drexel University, a private, non-profit institution. This large program admits up to $140 \mathrm{EdD}$ students annually with approximately 100 attending fully online and 40 attending hybrid offerings at the main campus and at a satellite program in Washington, DC. The essay features a qualitative course observation activity designed by Janesick (2011) to be used face-to-face and details how the activity has been adapted for virtual delivery at East Coast University. As a literature review revealed a paucity of published works on teaching observation qualitatively, the authors seek to contribute to the knowledge base with particular emphasis on faculty teaching in an online program. Based upon the East Coast University faculty's use of this observation activity, students develop increased understanding of the roles of perception and perspective in qualitative observation.
\end{abstract}

KEYWORDS

EdD programs, online EdD programs, teaching qualitative research, teaching virtually

A century ago, academics would have found it impossible to imagine teaching a qualitative research course in an online $\mathrm{EdD}$ program. In the 1920s, when Harvard awarded the first recipients the EdD degree, the seeds of what would become qualitative research were taking root. This was evident in the early works of sociologists in the Chicago School such as Park and Burgess' (1925), as well as with social anthropologists as shown in Margaret Mead's (1928) Coming of Age in Samoa (as cited in Cooley, 2013). As the methods of qualitative research coalesced and became more refined, ethnographic accounts of educational settings emerged with the first study of note conducted by George and Louise Spindler in the second half of the $20^{\text {th }}$ century (cited in Cooley, 2013).

On a parallel path, the seeds of online education were being planted in the form of correspondence courses with lectures delivered over the radio. Pennsylvania State University was the first institution of higher education to broadcast such courses in 1922 (Ferrer, 2019). Three years later in 1925, the National Home Study Council was established; in 2015 the name was changed to the Distance Education Accrediting Commission (Ferrer, 2019).

While these three innovations have encountered different challenges and successes in their respective fields over the course of their unilateral developments, their integration in the form of online EdD programs has given rise to a new set of questions, including how to effectively introduce scholarly practitioners to qualitative research through online teaching and learning. In this essay, we feature a method of virtually teaching qualitative observation to online EdD students. We situate the essay in a literature review on teaching qualitative research online. This review highlights the dearth of research on teaching qualitative research and observation as a research method in an online course. We also consider the areas for growth for both instructors and EdD students in online qualitative research methods courses. After introducing our EdD program and our stances as teachers and researchers, we describe our approach to teaching observation skills in an online qualitative research course. We conclude by offering recommendations for future research and practice.

\section{TEACHING QUALITATIVE RESEARCH ONLINE}

In the last decade, two literature reviews about teaching qualitative research have been published. The first literature synthesis by Wagner et al. (2019) examined 39 research studies
New articles in this journal are licensed under a Creative Commons Attribution 4.0 United States License. Program and is cosponsored by the University of Pittsburgh Press. 
published from 1999-2013 on teaching qualitative research methods. Seven themes were identified including experiential learning, practice-based materials and workshops, course structure, peer or collaborative work, apprenticeship model, competence of qualitative research trainers, and teaching resources. Although this review considered research on teaching qualitative research, five of the seven identified themes focused on student learning-notably reinforcing the significance of experiential learning (Cooper et al., 2012).

In contrast to Wagner et al.'s (2019) literature review, Snelson (2019) produced a scoping review of research based solely on scholarship on teaching qualitative research methods online. Using the TPACK framework, which defines teacher knowledge in terms of technological, pedagogical, and content knowledge, Snelson analyzed 11 articles; her findings indicated that "... online qualitative research methods educators choose course goals, instructional modules, and topics in a manner consistent with instructional design approaches" (p. 2799). Noticeably absent from Snelson's review was attention to experiential learning for online students, which was emphasized in the other reviews (Cooper et al., 2012; Wagner et al., 2019). However, Snelson's research called for greater attention to experiential learning in future studies of teaching qualitative research online.

As evidenced by both of these literature reviews, there is a paucity of works on teaching qualitative research methods online (Miskovic \& Lyutykh, 2017; Snelson, 2019). Miskovic and Lyutykh (2017) concluded that "[t]here are few studies on how to teach qualitative research, let alone how to go about it in an online format" (p. 2705). Snelson (2019) concurred:

Teaching practices in online qualitative research methods courses have become an increasingly important topic of inquiry in an age when a wide variety of online and distance education opportunities are available including online doctoral programs in which qualitative methods courses are an established part of the curriculum. ( $p$. 2799)

For instructors in online EdD programs, more research is required to inform pedagogy and practices related to teaching qualitative research methods in online classes.

With regard to pedagogy, scholarship on teaching qualitative research methods online highlights three areas for online instructors to consider. First, Kanzki-Veloso et al. (2018) asserted, "In addition to being an expert in research as a subject matter, teaching research online also requires the instructor to effectively blend technology, instructional strategies, and content" (p. 1). Second, Hunter et al. (2014) insisted that regardless of the teaching format, "the epistemological and ontological suppositions of qualitative research require a format that is interactive, engaging, and reflective-both traditional and distance must teach using interactive, engaging, and reflective methods" (p. 9). Last, Miskovic and Lyutykh (2017) argued that qualitative methods course instructors teaching in an asynchronous online setting should give careful consideration to certain inherent tensions:

(a) How to explain or enact the give-and-take occurrences of interviews on the static discussion board...? (b) How to 'type in' positionality and the role identity markers play in research, when both the instructors and the students remain mostly invisible to each other? [and] (c) [How to negotiate] ... the privileging of a written form in an online teaching platform [that] simultaneously challenges and liberates us in meeting the students through the text only? (p. 2714)

Creative instructional technologies and engaging learning experiences can help to address the inherent tensions and relative limitations posed by largely text-based communication in online educational settings (Gregory, 2018).

Moreover, within this limited body of work, few studies have focused on the teaching of specific qualitative research methods such as observation. Between the cited literature reviews and the search conducted for this paper, just three studies of teaching observation in an online qualitative methods course were identified. In the first study, the observation activity involved students watching a video and writing up fieldnotes (Steckler et al., 2001). In the second study, students practiced participant observation in the virtual world of an online game, World of Warcraft. Students developed avatars and entered the video game, where they interacted with other people in the game, and wrote fieldnotes to record their experiences (Snelson et al., 2017). In the third study (Kawulich \& D'Alba, 2019), students conducted ethnographic research in Second Life. Similar to the prior study, students created avatars and entered Second Life to interact with other people. While innovative in their use of technology to learn observation, these studies suggest that more research is needed to understand how observations skills can be taught and learned in an online course format.

\section{CONTEXT: DREXEL UNIVERSITY EDD PROGRAM}

In this section, we provide a summary of Drexel University's EdD Program. Additionally, each of the three authors reveals their researcher's stance. We end this section by describing the research sequence in our EdD Program.

\section{Brief Program Description}

Professors Phillips, Grant and Geller teach in the Drexel University online EdD Program. Uniquely, the virtual designation at Drexel University, a private, non-profit institution, can represent both students and faculty. While Drexel University itself is located in the Mid-Atlantic region, we three faculty live in North Carolina, Ohio, and California respectively, and our students, while primarily from the northeastern United States, are also from across North America, Asia, Europe and the Middle East.

This EdD program was founded in 2008-2009 and designed based on the principles defined in Shulman et al.'s (2006) Reclaiming Education's Doctorate: A Critique and a Proposal. As such, the Drexel EdD program's five learning objectives - our keystones - are tightly aligned with the Carnegie Project on the Education Doctorate guiding principles (CPED, 2020). Upon completion of our EdD program, our graduates will:

$\diamond$ Possess the ability to create and support learning communities that are the basis for sustainable change;

$\checkmark$ Develop the habits of mind and competencies to lead complex organizations shaped by global forces;

$\checkmark$ Develop the abilities to sustain their own leadership growth, to begin new careers in leadership or advance in their current careers; 
$\diamond$ Utilize the full range of emerging technologies to reach across generations, communicate effectively, and engage others; and,

$\diamond$ Exemplify the curiosity, inquiry skills, and scholarly competencies needed to investigate an idea, transform it and put into meaningful action.

As we write this paper, our EdD Advisory Council is in the process of adding a sixth learning objective that recognizes that our graduates address issues of social justice and lead actions to ensure the creation of more equitable organizations, communities, and policies.

The initial EdD program was a hybrid model delivered at three US locations; this program was delivered $40 \%$ face-to-face during monthly Executive Weekend sessions and 60\% online. In 2012, we added our first online cohort. Today our program admits up to 140 EdD students annually with approximately 100 attending the threeand five-year options fully online. The Drexel University EdD program became a member of the Carnegie Project for the Education Doctorate (CPED) in 2015 and was recognized as the 2019 CPED EdD Program of the Year.

According to the Drexel University website, the mission of this EdD program is to "enhance the preparation of professionals for leadership positions in a wide variety of educational and organizational environments; preparing them to address today's problems of practice." The majority of students are education professionals with $52 \%$ employed in Higher Education, $36 \%$ in $\mathrm{K}$ $12 /$ Charter School Education, and the remaining $12 \%$ hailing from a variety of fields including the US armed forces, government agencies, healthcare, corporate settings, non-profits, and as independent entrepreneurs.

The cohorts forge interactive communities of practice as they move through coursework and beyond (Wenger-Trayner, E. \& Wenger-Trayner, B., 2020). The courses feature scaffolded content within and across the curriculum. In the first year, students take the four core leadership courses based on the essential elements of systems thinking, transformational change, organizational design, and equity and justice. They also take the first four research courses which introduce the students to program evaluation, academic writing, and educational research. In the second year, students take four additional research courses-including a two-course sequence of Qualitative Research Methods and Data Analysis-and four concentration courses. During several of the leadership and research courses, students complete scaffolded "signature assignments." Signature assignments reflect the class content (leadership, academic writing, qualitative research, proposal development) and provide students with scaffolded developmental writing feedback to enhance the students' critical thinking and writing skills reflecting their transformation to "scholar/practitioners."

\section{Research Sequence in our EdD Program}

Research coursework begins in the first quarter of the program, when students draw on their tacit knowledge and professional experiences to gain an understanding of the scholarship of program evaluation to enhance their professional practice. Prior to beginning their study of educational research, they develop an understanding of the value of creating evidence-based arguments and deepen their understanding of leading systemic change to address "problems in practice" (CPED, 2020). For the last two quarters of their first year, they gain an overview of educational research and apply these learnings about research problems and questions to their initially framed problem of practice choosing to study it through their preliminary application of quantitative, qualitative, or mixed research methods. By the end of the first year, Drexel University online EdD students have created initial writings that introduce their selected research problem in practice, define the purpose of their study and begin to identify the questions that will frame their dissertation study. They have begun to develop their foundational knowledge of the scholarship and published practice related to their problem and they are actively considering possible research methods. In the context of this classwork, our EdD students have been introduced to the dissertation proposal for a problem of practice.

In the second year, students take a deep dive into qualitative research, studying their proposed problem of practice in a pilot qualitative study. They similarly take a lab-based quantitative course and apply elements of quantitative research and mixed methods to their understanding of their problem of practice research. In their eighth quarter, the students begin to work with a Supervising Professor who serves as the chair for their dissertation journey, and, simultaneously, they participate in a Doctoral Seminar where they integrate the prior learnings about evidence-based practice with an enlightened understanding of educational research. In this seminar they begin working on the three chapters that are the basis for their proposal. In their ninth and final quarter of coursework, they work with their Supervising Professor to bring their proposal to readiness for committee review. In the third year, students complete their coursework and with the mentoring of their Supervising Professor gain their committee members' approval for their research proposal and begin their dissertation research process.

\section{WHO ARE WE AS ONLINE INSTRUCTORS AND QUALITATIVE RESEARCHERS?}

In line with the spirit and tradition of qualitative researchers, we offer insight on our positionality and stances as teachers and researchers. Each author situates themselves in their identified epistemology, ontology, and axiology.

Dr. Joy Phillips believes that one's researcher's stance is constantly evolving, as we are all in the process of becoming. Her White childhood in the segregated South was dominated by reading anything she could get her hands on and asking "why." In adolescence during the Civil Rights Movement, guided by her mother, she followed a college preparatory track that emphasized math and science, with little attention to the humanities. An undergraduate degree in a STEM field led to a decade long career chapter as a scientist. It was not until a master's program that she was introduced to the social sciences, with which she fell in love, a passion she had never felt for math and science. This graduate degree led to a new career chapter in non-profit administration and leadership in organizations that provided services to underserved families and children. Undergirding both chapters was a focus on education and teaching and continuing to ask "why;" all eventually led to $\mathrm{ahD}$ and a third career chapter in academia.

From these experiences, Phillips discovered much about herself, including that she learned best from observing, listening, talking with people, and engaging with complex and contradictory ideas. Gradually she came to know this as her epistemological stance. From this emerging understanding came a recognition of her worldview, or ontology, as a social constructivist. Influencing both 
were values and beliefs, axiological views, that individuals are shaped by their own personal experiences, that all people have important stories to tell, and that knowing is always partial and tentative.

Dr. Kristine Grant is a cisgender African American woman who grew up in Northern Kentucky and attended school in the district that her father, aunts, and uncles helped to desegregate. Her first love was stories-the stories her elders told at family gatherings, the stories she read from the many books that she borrowed from the library every week, and the stories and poems that she wrote and shared. The first in her family to attend college, Grant enrolled in an African American Studies course the fall of her first year. There she learned the history and language to both contextualize and connect her family's and community's experiences to the larger legacy of people of African descent. As a Sociology and African American Studies major, Grant conducted her first research study the summer of her junior year and discovered her second love-qualitative research. After graduating, she earned a PhD in Urban Education with the expressed intention to honor her elders and ancestors by giving back in her role as professor.

Listening to the stories of people of color, understanding how they make meaning of their lived experiences, and examining how the stories of and meaning assigned to their lived experiences contrast with the oppressive, controlling narratives prominent in US society-together, this in/forms the basis of her Black feminist epistemology. Ontologically, Grant's worldview is rooted in the intersectionality of her identities and lived experiences as a woman of African descent. In alignment with Patricia Hill-Collins (1991), she abides by an ethic of care, placing value on individual expressiveness, understanding the appropriateness of emotions, and developing a capacity for empathy.

Before joining academia, Dr. Kathy Geller was a management education and organizational learning professional; she frequently spoke about "truth with a small t" when she was facilitating leadership programs at various locations around the world. Her philosophy of facilitation was based on "knowing oneself and honoring the other." Residing in Hong Kong, Kuwait and Malaysia and working for a British Bank focused in Asia, Africa and the Middle East, Geller learned to appreciate the cultural basis of identity, to question her worldviews gained from living and working in Texas, Maryland and Florida, and to recognize that Emily Post's rules of etiquette worked only for a few cultures (although they had been taught as if they were global).

These experiences and others informed Geller's epistemology as a scholar/practitioner and faculty member where she found natural alignment with Gergen's (1985) representation of the social constructivist view reflecting her ontology that "truth comes in many representations." Her axiological values in leadership draw on the concept of an ethic of care (Noddings, 2013) and recognizing and honoring difference. While emersed in her culture of origin for these recent 12 years, Geller draws on these global life lessons as she teaches qualitative research.

The faculty use their paradigms and philosophies to personalize the delivery of the content and bring it to life. However, course design, including the readings and assignments, are consistent across the cohorts. The next section focuses on the qualitative research methods course sequence.

\section{QUALITATIVE COURSE SEQUENCE: DESIGN OF EDUC 836-837}

In our EdD program, we teach qualitative research in a twocourse sequence. Since Drexel University follows the quarter system, each course runs for 10-weeks; thus, this two-course sequence is taught over 20 weeks. A quarter break of approximately two weeks occurs for students between the two courses. EdD students may elect a three-year or a five-year program of study.

In the three-year EdD program design, the initial course, EDUC 836, is taught in year two, in the fifth quarter. The second course, EDUC 837, is taught in the quarter immediately following, in the sixth quarter. In the five-year program, students take one course per term and the two qualitative courses are taught in year four, during the $13^{\text {th }}$ and $14^{\text {th }}$ quarters. Both plans of study include the same courses.

The primary learning goals of the initial qualitative course are to introduce EdD students to a set of five qualitative traditions, or methodologies including case study, phenomenology, narrative, ethnography, and grounded theory (Creswell \& Poth, 2018). Students select one of these traditions to conduct a pilot study related to their identified problem of practice. They construct a pilot study proposal and protocols, and following instructor approval, collect qualitative data through three one-to-one interviews and one focus group with three to four participants.

Over the quarter break, students may begin the process of transcribing the recordings (audio and/or video) of the interviews and focus group. In the second course, EDUC 837, students have the first two weeks to complete their data transcriptions. We urge students to personally transcribe at least one transcript, but we are yielding to the emerging reality that transcription services are fully integrated into computer software. For example, Zoom, the online video platform provided to our students, allows them to conduct their interviews and focus group online, and provides a written transcription supported through Otter.ai.

In this second course, students focus on coding their transcripts and analyzing their data following Saldaña's (2016) guidance through first cycle coding, transitional steps after first cycle coding, and second cycle coding. We require students to demonstrate their progression through the coding process in textual and graphic form to illustrate how they arrive at their selection of final themes and subthemes.

Ultimately, students produce a final report of their pilot study including problem overview, methodology, analysis, findings, conclusions, and recommendations. In Summer 2020, we began to score the final papers with a detailed 30-point rubric; this assignment is a Signature Assignment for students that enables them and their instructors to assess their progress with skill development and proficiency that will be evidenced later in their problem of practice dissertation proposal and subsequent study. Regardless of what research methodology students select to conduct their dissertation, we believe that demonstrating a level of proficiency in qualitative research is useful and important to advancing students' future success as scholarly practitioners (Lochmiller \& Lester, 2016; Slayton \& Samkian, 2017).

In the second course in the qualitative course sequence, we also introduce students to qualitative observation through two learning activities. One observation activity is conducted individually; pre-COVID, students selected a public setting with a lot of action and recorded in writing as much as possible about what they saw. During 
COVID, instructors shifted to students conducting a written observation of a film clip. The other observation activity is conducted in a group format and is composed of "observing a still life" (Janesick 2011). The still life activity is used to explain the elements of observation and the requisite skills and is fully described below.

\section{Observation Activity}

The primary learning objective of the still life observation activity is to facilitate students' awareness of the role of perception and perspective in their qualitative practice. The featured group observation activity is conducted virtually, via the web-based video platform Zoom. This activity was developed for face-to-face delivery by Valerie Janesick (2011, pp. 25-26), and Phillips initially used it in a face-to-face qualitative research course. Converting this lesson for online delivery was not difficult. To assist with understanding the activity intent, the face-to-face version is described first, followed by the online conversion.

\section{Face-to-Face Version}

As Janesick (2011) explained, the purpose of this activity is for participants "to observe and describe an assortment of objects on a table" (p. 25). Aligning with the arts, Janesick called this arrangement a "still life scene" (p. 25). The items included in the still life are the instructor's choice, composed of random objects from the home or office. According to Janesick, the assortment should contain at least five items of various shapes, sizes, colors, texture, etc. This arrangement is casually displayed in such a way that students may see the front, side, or back of an object.

Students are seated around the table enabling them to see a slice of the still life; they are not able to move to see the arrangement from a different angle. The instructions are to spend approximately 20 minutes observing the still life and writing as many details as possible about what they see from their position, while remaining silent throughout the activity. The notetaking is to be done in a fieldnote format with separate columns for description and for reflective notes.

After completing the observation, another 20 minutes is spent having the students read aloud to the full group what they recorded Typically, as students report out, those arrayed around the table express surprise as they hear the description of items that they viewed from one angle, detailed from a different angle. Surprise is also expressed about the different degrees of detail in each report, as some students read a fairly brief list of items, while others provide substantial to complex details.

Phillips has noted that students initially comply with the activity instructions with some amount of unspoken skepticism, voiced later, about whether the observation exercise would have much meaning to them. However, as and after the students share the individual responses, students often marvel as they gradually recognize the unconscious assumptions they had made. Phillips concludes this activity by explicitly acknowledging that the process promotes increased individual awareness of perception and perspective.

\section{Virtual Version}

The virtual version of this activity includes all the elements of the face-to-face version with a few adjustments. Instead of having students seated around a table on which the still life is arranged, the virtual participants engage in the observation activity in small teams of three to four people in Zoom breakout rooms. Instead of having the group observe a single still life scene, each group is provided a different photograph of the same setting from a different angle.

To prepare, the instructor creates a still life scene as described above; then, the instructor takes a set of photographs of the scene in a 360-degree fashion. Each photo represents a sliced view of the still life, mimicking the face-to-face individual views. See Figure 1 for example photographs from Phillips; these are four of eleven total photos in the set, roughly representing the still life at 90-degree angles.

Figure 1. Examples of Still Life Photographs

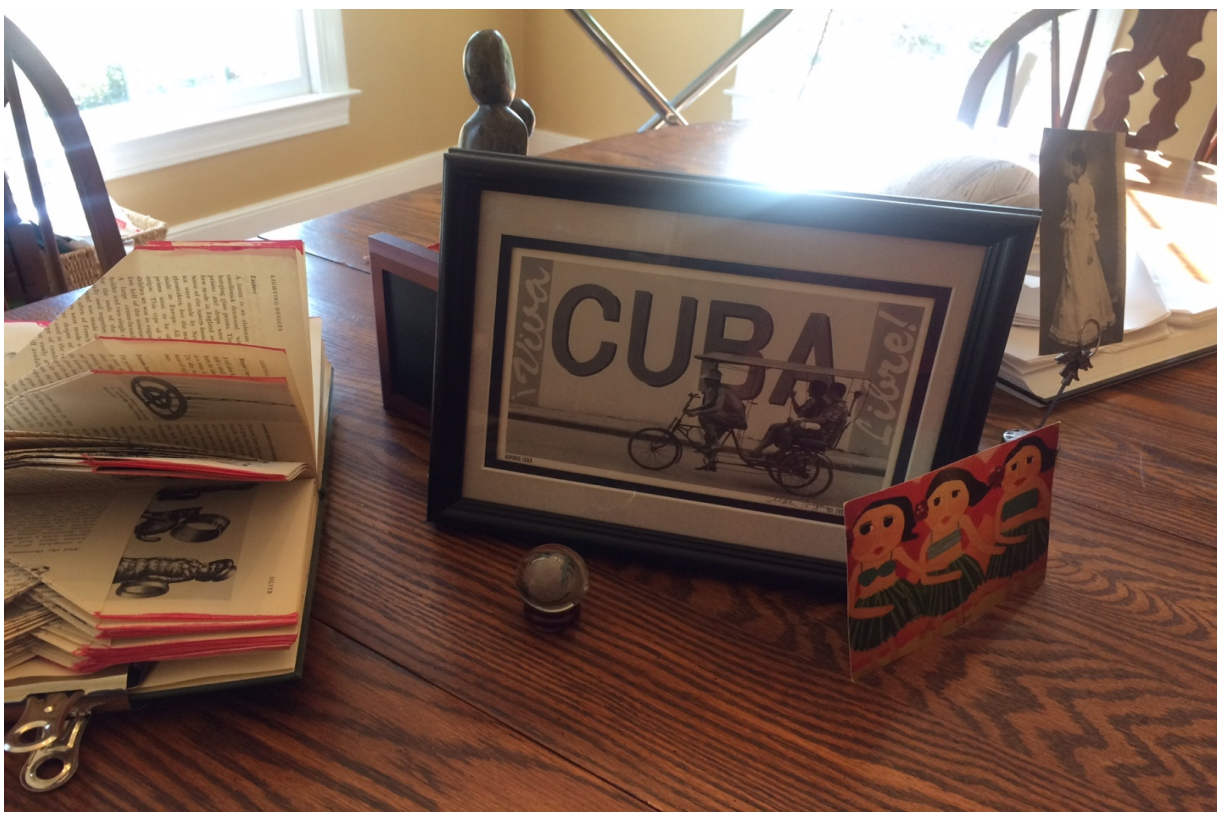



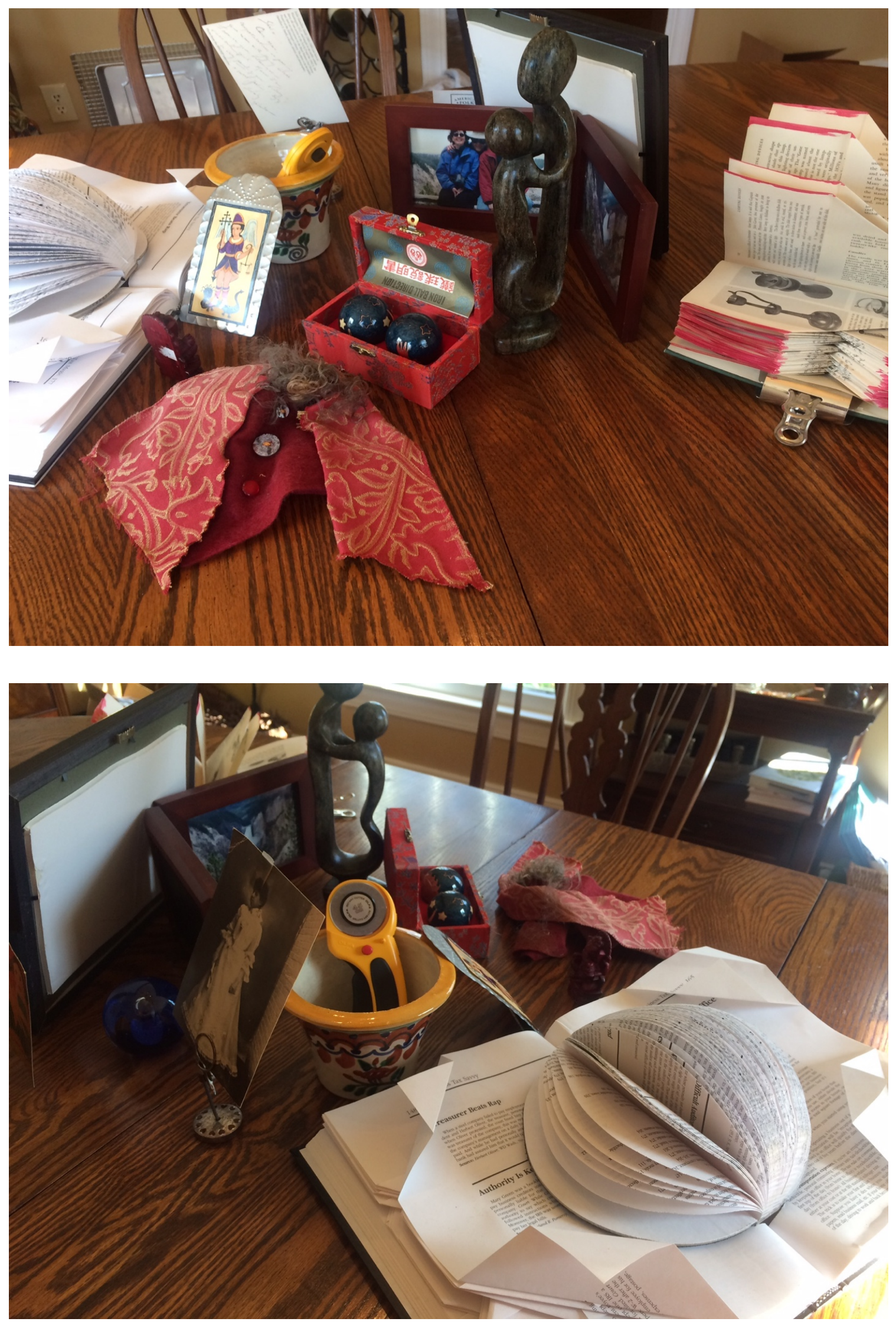


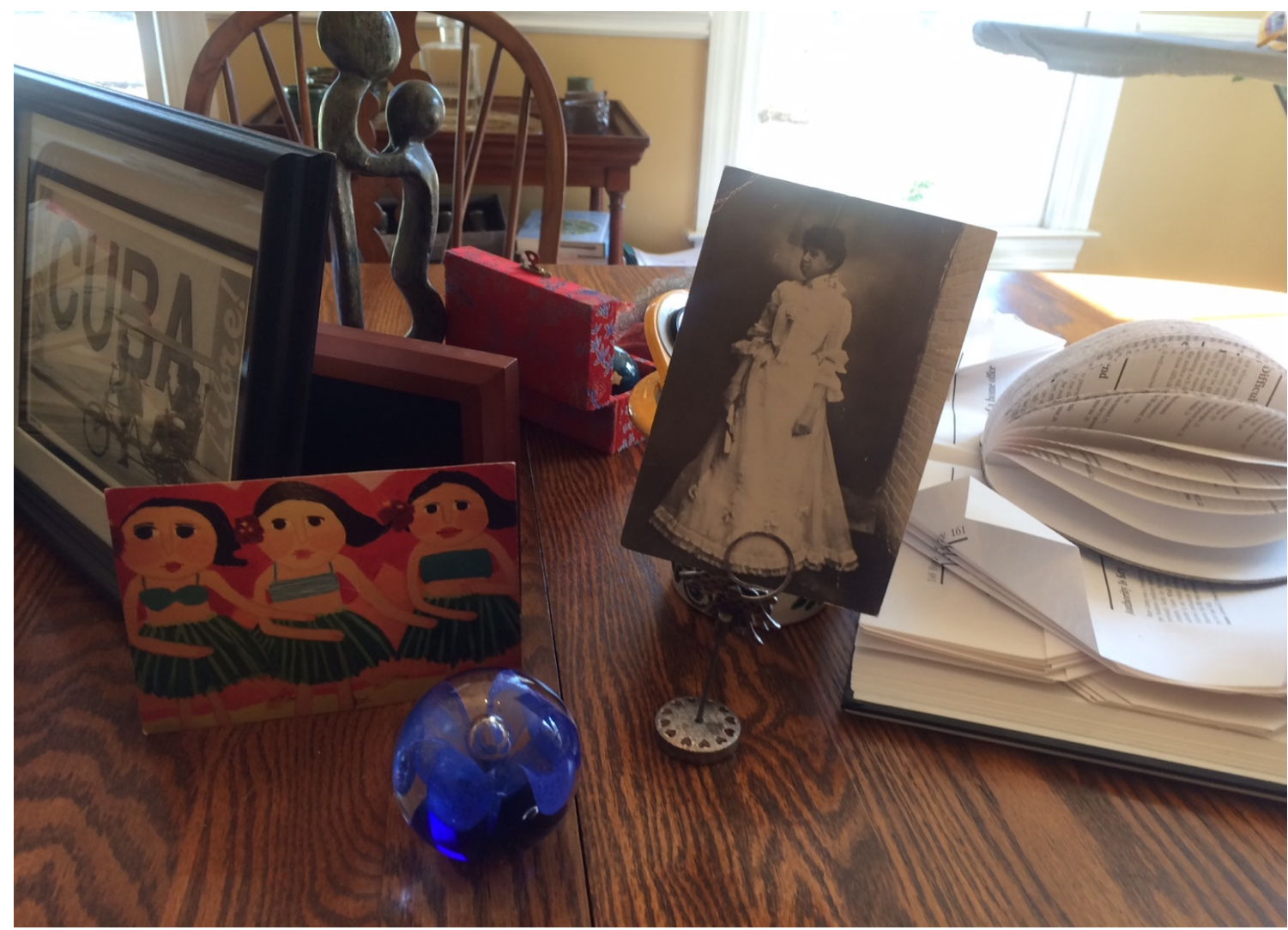

In the virtual version, the instructor provides students the same general directions as above (e.g., 20 minutes of silent observation, recorded fieldnotes, etc.) along with the specific virtual instructions. At the end of the allotted time, the instructor calls students back from the breakout rooms into the full group Zoom, and all report out as previously described.

Variations of the virtual activity are easily made such as having small group members discuss their individual accounts of the same photo before returning to the full group. Another option for students unable to attend synchronously is for the instructor to delay posting the class session Zoom recording, to email those students one of the photographs, and to have them do the activity individually before posting their responses to the Blackboard Discussion Board.

Regardless of the face-to-face or virtual formats, students report their observations in a quite similar fashion with less, more, or much detail. The full group reflection yields the same sort of surprised responses, and the instructor ends the experiential, online session with the same focus on being aware of the role of perception and perspective in their observation practice.

\section{DISCUSSION AND CONCLUSION}

Our adaptation of Janesick's (2011) observation activity adds to the small selection of works on teaching observation as a qualitative research skill in an online learning environment. Previous articles on teaching observation skills in an online course featured the use of a video (Steckler et al., 2001) and two online games, World of Warcraft (Snelson et al., 2017) and Second Life (Kawulich \& d'alba, 2019). Our work seeks to build on Steckler et al. (2001); by providing a description of our actual lesson, we seek to provide an example of an effective instructional strategy for teaching qualitative methods online.

Our work also contributes to the scholarship of teaching qualitative research methods, specifically in online classrooms. Teaching qualitative research online requires a format that is "interactive, engaging and reflective" (Hunter et al, 2014, p. 9). The featured experiential learning activity incorporated technology and instructional strategies to introduce students to qualitative research broadly, and observation specifically. By making use of the breakout rooms in Zoom, we resolved some of the inherent tensions in online teaching and learning. The use of Zoom (or similar videoconference platforms) in online teaching reduced the invisibility of teachers and students and promoted real time exchanges that are not mediated by text alone. By placing students into breakout rooms and bringing them back together for a whole group reflection and discussion, this learning activity fosters student interaction and engagement.

Teaching qualitative research online "blends technology, instructional strategies and content" (Kanzki-Veloso et al., 2018, p. 1). By attending to these requirements, online instructors can mitigate some of the inherent tensions associated with online teaching and learning, such as static discussion boards, invisible identities and positionalities, and privileged written formats (Miskovic \& Lyutykh, 2017). More importantly, learning about qualitative research methods in an online EdD program has clear implications for students' development as scholarly practitioners. Developing EdD students' qualitative research skills can shape their approaches to leadership in areas such as communication, community-building 
and problem-solving (Gregory, 2018; Lochmiller \& Lester, 2016; Slayton \& Samkian, 2017).

This observation activity is one of several in the Drexel University online delivery of qualitative research methods that draws on the community of practice concept (Wenger-Trayner \& WengerTraynor, 2020) to foster a collaborative learning environment. Additional assignments that include online collaborative methods are the use of a Critical Friends Process to upskill qualitative interviewing, a virtual coding experience that fosters knowledge of cycle one and cycle two coding methods as the basis for research findings, and pilot study presentations that focus on using evidence in leading change. With this essay, the authors seek to help professors in online EdD programs re-imagine teaching and learning qualitative research for our emerging generation of virtually based scholar-practitioners.

\section{REFERENCES}

Carnegie Project on the Education Doctorate. (2020). Guiding principles for program design, https://cped.memberclicks.net/the-framework

Cooley, A. (2013). Qualitative research in education: The origins, debates, and politics of creating knowledge. Educational Studies, 49(3), 247-262. https://doi.org/10.1080/00131946.2013.783834

Cooper, R., Chenail, R. J., \& Fleming, S. (2012). A grounded theory of inductive qualitative research education: Results of a meta-data-analysis. The Qualitative Report, 17(52), 1-26. Retrieved from https://nsuworks.nova.edu/tqr/vol17/iss52/3

Creswell, J. \& Poth, C. (2018). Qualitative inquiry and research design: Choosing among five approaches (4th ed.). SAGE Publications.

Ferrer, D. (July 17, 2019). History of online education. The Quad Magazine. https://thebestschools.org/magazine/online-education-history/

Gergen, K. (1985). The social constructionist movement in modern psychology. American Psychologist. 40(3). 266-275. DOI: 10.1037//0003-066X.40.3.266

Gregory, K. (2018). Online communication settings and the qualitative research process: acclimating students and novice researchers. Qualitative Health Research, 28(10), 1610-1620. https://doi.org/10.1177/1049732318776625

Hill Collins, P. (1991). Black feminist thought: Knowledge, consciousness, and the politics of empowerment. Routledge.

Hunter, C., Ortloff, D., \& Winkle-Wagner, R. (2014). Out of our comfort zones: Reflections about teaching qualitative research at a distance. The Qualitative Report, 19(45), 1-24. Retrieved from https://nsuworks.nova.edu/tqr/vol19/iss45/3

Janesick, V. J. (2011). Stretching exercises for qualitative researchers (3rd ed.). SAGE Publications.

Kanzki-Veloso, E., Orellana, A., \& Reeves, J. (2018). Teaching qualitative research online: Using technology to leverage student engagement. FDLA Journal, 3(6), 1-9. Retrieved from https://nsuworks.nova.edu/fdlajournal/vol3/iss $1 / 6$

Kawulich, B., \& d'alba, A. (2019). Teaching qualitative research methods with Second Life, a 3-dimensional online virtual environment. Virtual Reality, 23(4), 375-384

Lochmiller, C. R., \& Lester, J. N. (2016). Conceptualizing practitionerscholarship for educational leadership research and practice. Journal of Research on Leadership Education, 12(1), 3-25. doi:10.1177/1942775116668525

Miskovic, M., \& Lyutykh, E. (2017). Teaching qualitative research online to leadership students: Between firm structure and free flow. The Qualitative Report, 22(10), 2704-2721. Retrieved from https://nsuworks.nova.edu/tqr/vol22/iss10/12

Noddings, N. (2013). Caring: A relational approach to ethics and moral education ( $2^{\text {nd }}$ ed.). University of California Press

Saldaña, J. (2016). The coding manual for qualitative researchers (3rd ed.). SAGE Publications.
Shulman. L. S., Golde, C. M., Bueschel, A. C., \& Garabedian, K. J. (April 01, 2006). Reclaiming education's doctorates: A critique and a proposal. Educational Researcher, 35(3), 25-32.

Slayton, S., \& Samkian, A. (2017). Scaffolding learning for practitionerscholars: The philosophy and design of a qualitative research methods course. Journal of Research on Leadership Education, 12(1), 51-71. https://doi.org/10.1177/1942775116663713

Snelson, C. (2019). Teaching qualitative research methods online: A scoping review of the literature. The Qualitative Report, 24(11), 2799-2814. Retrieved from https://nsuworks.nova.edu/tqr/vol24/iss11/9

Snelson, C., Wertz, C., Onstott, K., \& Bader, J. (2017). Using World of Warcraft to teach research methods in online doctoral education: A student-instructor duoethnography. The Qualitative Report, 22(5), 14391456. Retrieved from http://nsuworks.nova.edu/tqr/vol22/iss5/18/

Steckler, A., Farel, A., Bontempi, J. B., Umble, K., Polhamus, B., \& Trester, A. (2001). Can health professionals learn qualitative evaluation methods on the World Wide Web? A case example. Health Education Research, 16(6), 735-745. http://doi.org/10.1093/her/16.6.735

Wagner. C., Kawulich, B., \& Garner, M. (2019). A mixed research synthesis of literature on teaching qualitative research methods. SAGE Open, 9(3), 1-18. https://doi.org/10.1177/2158244019861488

Wenger-Trayner, E. \& Wenger-Trayner, B. (2020). Resources for social learning: Publications. https://wenger-trayner.com/introduction-tocommunities-of-practice/ 